\title{
The angiogenic properties of Kaposi's sarcoma- associated herpesvirus encoded G-protein coupled receptor are reduced by flavopiridol, an inhibitor of cyclin-dependent kinase 9
}

\author{
Harris McFerrin ${ }^{1 *}$, Magdelena Angelova², Elizabeth Abboud ${ }^{2}$, Anne Nelson $^{2}$, Aline Betancourt ${ }^{2}$, Gilbert Morris $^{3}$,
} Bryan Shelby ${ }^{4}$, Cindy Morris ${ }^{2}$, Deborah Sullivan ${ }^{2}$

From $12^{\text {th }}$ International Conference on Malignancies in AIDS and Other Acquired Immunodeficiencies (ICMAOI)

Bethesda, MD, USA. 26-27 April, 2010

Kaposi's sarcoma-associated herpesvirus (KSHV/HHV8) has been identified as the etiologic agent of Kaposi's sarcoma (KS), a multifocal highly vascularized neoplasm that is the most common malignancy associated with AIDS. Although highly active antiretroviral therapy has decreased the incidence of KS, it remains an incurable tumor for which there is no established treatment. Due to the vascular nature of $\mathrm{KS}$, an anti-angiogenic therapeutic approach is attractive. The KSHV-encoded G-protein-coupled receptor (vGPCR) is required and sufficient to initiate angiogenesis and tumorigenesis. Recent evidence suggests that inhibition of P-TEFb, a transcriptional elongation factor composed of cyclin dependent kinase 9 (CDK9) and its regulatory partner cyclin $\mathrm{T}$, is anti-angiogenic.

We hypothesized that flavopiridol, a novel inhibitor of CDK9, would inhibit vGPCR-induced angiogenesis by downregulating expression of angiogenic growth factors and/or Bcl-2. To test this hypothesis, in vitro and in vivo angiogenesis assays were carried out using primary human umbilical vein endothelial cells (HUVECs) transduced with either a control or a vGPCR-expressing retroviral vector and then treated with flavopiridol. Our results show that CDK9 activity is increased in vGPCRexpressing HUVECs and that pretreatment with $50 \mathrm{nM}$ flavopiridol inhibited vGPCR-induced migration and capillary tubule formation. These results correlated with

* Correspondence: hmcferri@xula.edu

'Department of Biology, Xavier University of Louisiana, New Orleans, LA, USA Full list of author information is available at the end of the article a significant decrease in expression of genes encoding the angiogenic factors VEGF-A and VEGF-C and the pro-survival factor Bcl-2. Initial studies to determine the molecular mechanisms by which CDK9 affects angiogenesis demonstrated that HUVECs treated with bFGF and VEGF had increased CDK9 activity as well as increased expression of the major isoform of $\mathrm{Cdk} 9_{42}$ and cyclin T. Although Cdk9 was described in the literature as a general transcription factor, we have observed that inhibition of CDK9 by flavopiridol decreased the expression of Bcl-2 but not $\mathrm{p} 21$ in HUVEC. Together these results suggest that CDK9 plays a role in mediating transcriptional regulation of vGPCR responsive genes and implicate CDK9 as a potential target to reduce vGPCR-enhanced endothelial cell survival, angiogenesis, and tumorigenesis. Experiments are currently under way to determine whether CDK9 is directly activated upon vGPCR expression and whether inhibition of CDK9 activity suppresses KSHV-enhanced angiogenesis and tumorigenesis in vivo.

\section{Acknowledgements \\ This article has been published as part of Infectious Agents and Cancer Volume 5 Supplement 1, 2010: Proceedings of the $12^{\text {th }}$ International Conference on Malignancies in AIDS and Other Acquired Immunodeficiencies (ICMAOI).The full contents of the supplement are available online at http://www.biomedcentral.com/1750-9378/5?issue=S1.}

\section{Author details}

'Department of Biology, Xavier University of Louisiana, New Orleans, LA, USA. 'Department of Microbiology and Immunology, Tulane University School of Medicine, New Orleans, LA, USA. ${ }^{3}$ Program in Lung Biology, Department of Pathology, Tulane University School of Medicine, New 
Published: 11 October 2010

doi:10.1186/1750-9378-5-S1-A75

Cite this article as: McFerrin et al:: The angiogenic properties of Kaposi's sarcoma-associated herpesvirus encoded G-protein coupled receptor are reduced by flavopiridol, an inhibitor of cyclin-dependent kinase 9 . Infectious Agents and Cancer 2010 5(Suppl 1):A75.

Submit your next manuscript to BioMed Central and take full advantage of:

- Convenient online submission

- Thorough peer review

- No space constraints or color figure charges

- Immediate publication on acceptance

- Inclusion in PubMed, CAS, Scopus and Google Scholar

- Research which is freely available for redistribution

Submit your manuscript at www.biomedcentral.com/submit
C Biomed Central 